\title{
Fingertip Replantation with the Use of a Long Vein Graft: Training Young Surgeons in a Feasible Technique to Maintain Optimal Results
}

\author{
Tomohiro Shiraishi, MD ${ }^{1}$ Masakazu Kurita, MD, $\mathrm{PhD}^{1}$ \\ Kiyonori Harii, MD, $\mathrm{PhD}^{1}$ \\ ${ }^{1}$ Department of Plastic Surgery, Kyorin University School of Medicine,
Tokyo, Japan
}

J Reconstr Microsurg Open 2016;1:100-105.

\author{
Keigo Narita, $\mathrm{MD}^{1} \quad$ Akihiko Takushima, $\mathrm{MD}, \mathrm{PhD}^{1}$
}

Address for correspondence Tomohiro Shiraishi, MD, Department of Plastic Surgery, Kyorin University School of Medicine, 6-20-2 Shinkawa Mitaka, Tokyo, Japan (e-mail: shiraishi-tky@umin.ac.jp).

Digital replantation using microsurgery has progressed remarkably since the first thumb replantation report by Komatsu and Tamai in $1968 .^{1}$ It is now a common hand surgery procedure, and even fingertips are replanted with high success rates between 70 and $90 \%{ }^{2-7}$ A systematic review in 2011 found good outcomes in terms of both the success rate and postoperative function. ${ }^{8}$

In many reports, the successful fingertip replantations are those performed by well-experienced surgeons. ${ }^{4}$ However, younger surgeons should be trained in operative techniques for fingertip replantation, as most severed fingers are replanted in an emergency setting where expert microsurgeons may not always be present. Therefore, we retrospectively investigated the fingertip replantation cases in our hospital that were performed by young surgeons who were instructed by one experienced surgeon (T.S.). We found that a procedure using a long vein graft produced better results even for young surgeons. received

September 5, 2016 accepted after revision June 22, 2016 published online August 8, 2016
DOI http://dx.doi.org/ $10.1055 / \mathrm{s}-0036-1587339$ ISSN 2377-0813.
Copyright $\odot 2016$ by Thieme Medical Publishers, Inc., 333 Seventh Avenue, New York, NY 10001, USA. Tel: +1(212) 584-4662.
License terms

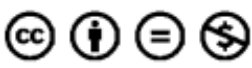




\section{Patients and Methods}

Between January 2006 and December 2014, 76 consecutive fingertip replantations in 67 patients distal to Tamai's zone I or II were performed at the Kyorin University Hospital. The sample included 56 male and 11 female patients with ages ranging from 1 to 83 years (mean: $45 \pm 18.9$ years). We retrospectively assessed the conditions of the fingertips, techniques used, procedure details, and complications that occurred.

For the 76 fingertips, replantation with only arterial anastomosis was attempted in seven fingers by young surgeons, but only two fingertips survived. For the remaining 69 fingertips, replantation involved both arterial and venous anastomoses. These cases were divided into three groups, A, $B$ and $C$, according to the operative procedure. The operative procedures for each group are detailed as follows. In group A, an improved procedure with the aggressive use of a long vein graft was utilized. The choice of procedure was not randomized, though no specific reasons dictated the choice of procedure. Each of the 69 replantations was performed by one of several young surgeons in an emergency setting while instruction was given by one experienced surgeon (the principal author, T.S.), who assisted them when the anastomosis was thought to be technically difficult or could result in complications. All patients received an intravenous drip of heparin, prostaglandin E1, and urokinase, and all remained on bed rest for at least 1 week. The features of the injuries and the survival rates between groups were statistically analyzed.

\section{Operative Procedure}

Group A (long vein graft): A relatively long vein graft, primarily harvested from the dorsum of the foot, was first anastomosed to an arterial stump in the amputated fingertip before it was fixed to the proximal stump ( - Fig. 1). This procedure was similar to the "pre-osteosynthesis vein graft technique" described by Ikeda et $\mathrm{al}^{9}$ in 1994, but skeletal fixation was not applied in most cases, consistent with Sabapathy et al. ${ }^{10}$

The vein graft was long enough to reach the proximal phalanx, which is much longer than previously reported. ${ }^{7,9}$ This long vein graft could usually be harvested from the dorsum of the foot, where the subcutaneous veins have various branches with sizable diameters that are adequate for grafting. The anastomosis between the artery in the amputated fingertip and the vein graft was first performed on the back table where the amputated fingertip and vein graft could be placed under a microscope and held in the optimal positions for anastomosis (-Fig. 2). After completing the anastomosis, heparinized saline solution was injected into the opposite stump of the vein graft to check the patency or the leakage of the anastomotic site. Occasionally, this procedure revealed damage in the distal artery of the amputated fingertip, which is difficult to detect without a saline solution injection (-Fig. 3). When a damaged artery was found, it was repaired or another

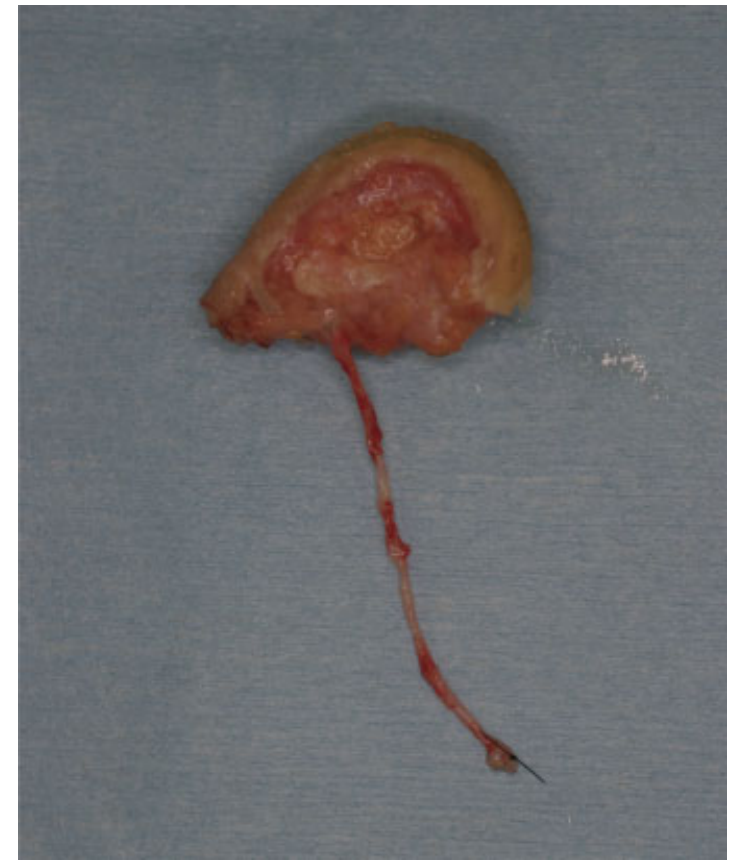

Fig. 1 A long vein graft is first anastomosed to the arterial stump in the amputated fingertip and then anastomosed to the arterial stump in the proximal finger stump.

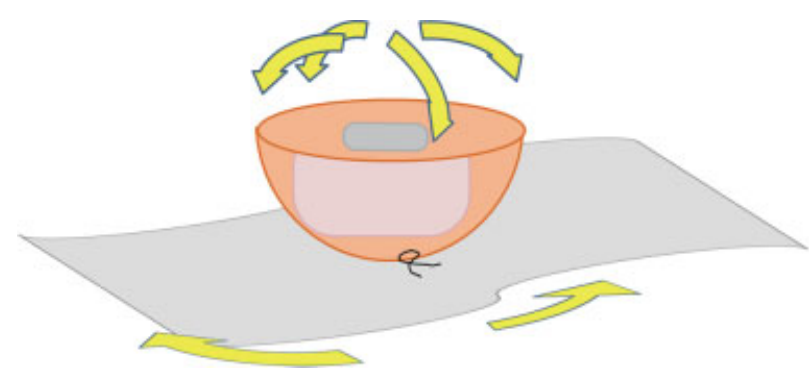

Fig. 2 The tip is sutured to gauze on the table. The position of the amputated fingertip and vessels can be arranged freely on the table.

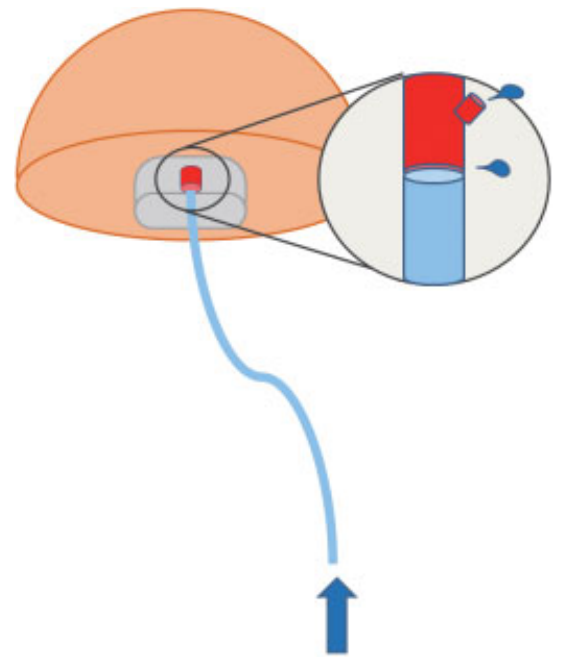

Fig. 3 The artery of the amputated fingertip occasionally has a small hole or torn-off branches due to the injury, which are difficult to find. This damage becomes feasible to detect when heparinized saline solution is gently injected into the vein graft stump. 
artery was chosen for anastomosis. After completion of the vein graft on the back table, the amputated fingertip was fixed to the proximal stump by suturing the tissues or using a simple K-wire bone pin. The long vein graft was then led to the artery of the amputated stump that was exposed proximally to the point at one half of the middle phalanx and not distally to this point. Finally, an end-to-end anastomosis was performed between the artery of the proximal stump and the vein graft stump. The digital bones were preserved whenever possible.

Group B (short vein graft): The anastomoses of the vessels were achieved after the amputated fingertip was fixed to the proximal stump. A short vein graft that was as long as the arterial defect was used when the gap between the arteries was long.

Group C (no vein graft): No vein graft was used for the arterial anastomosis.

In each group, the drainage veins were anastomosed in all cases. A vein graft was used when the distance between the veins was large and the veins were difficult to anastomose without a vein graft.

\section{Statistical Analysis}

One-way analysis of variance and chi-square tests were used to compare the demographic data across the three groups. Mann-Whitney U test was used to compare the survival rates across the three groups. Chi-square tests were used for all other comparisons. $P$-values $\leq 0.05$ were considered statistically significant.

\section{Results}

Group A consisted of 42 fingers in 39 patients, group B consisted of 6 fingers in 5 patients, and group $C$ consisted of 21 fingers in 17 patients. The amputation conditions in each group are shown in - Table $\mathbf{1}$. No statistically significant differences were seen in the patient characteristics, including the site and type of injury, between the groups.

All 42 replanted fingertips survived in group A (100\% survival), 5 of 6 fingertips survived in group B ( $83 \%$ survival), and 17 of 21 fingers survived in group C (81\% survival) (-Table 2). There was a significant difference in survival between the three groups $(p=0.003)$. There also was a significant difference between the vein graft group (A and $B$ combined) and the no graft group ( $C ; p=0.012)$ and between groups $A$ and $B(p=0.008)$. Moreover, one arterial thrombosis and one venous thrombosis occurred in group $C$, which were salvaged by reanastomosis (-Table 2 ).

Our grouping of $A, B$, and $C$ is focused on the method of vein graft usage for arterial anastomosis, while the rates of vein graft usage for venous anastomosis in each group are listed in - Table 3. There was a significant difference in the usage rates of a vein graft for venous anastomosis between the three groups $(p=0.008)$. There was also a significant difference in the survival rates between the cases with and without vein grafts for venous anastomosis $(p=0.04)$.
Table 1 Patient demographics and the condition of the amputated fingertips in each group

\begin{tabular}{|c|c|c|c|}
\hline \multirow[t]{2}{*}{$\begin{array}{l}\text { Mean age } \\
\text { (range) }\end{array}$} & $\begin{array}{l}\text { A: long } \\
\text { vein graft }\end{array}$ & $\begin{array}{l}\text { B: short } \\
\text { vein graft }\end{array}$ & $\begin{array}{l}\text { C: no } \\
\text { vein graft }\end{array}$ \\
\hline & $44(18-69)$ & $48(36-68)$ & $47(22-83)$ \\
\hline \multicolumn{4}{|l|}{ Gender } \\
\hline Male & 35 & 4 & 15 \\
\hline Female & 4 & 1 & 2 \\
\hline \multicolumn{4}{|c|}{ Amputated finger } \\
\hline Thumb & 7 & 1 & 2 \\
\hline Index & 12 & 3 & 4 \\
\hline Middle & 16 & 1 & 9 \\
\hline Ring & 5 & 1 & 6 \\
\hline Little & 2 & 0 & 0 \\
\hline \multicolumn{4}{|c|}{ Amputated level (Tamai zone) } \\
\hline Zone I & 20 & 2 & 11 \\
\hline Zone II & 22 & 4 & 10 \\
\hline \multicolumn{4}{|c|}{ Type of injury } \\
\hline Clean & 14 & 3 & 6 \\
\hline Blunt & 13 & 1 & 7 \\
\hline Crush & 9 & 2 & 6 \\
\hline Avulsion & 6 & 0 & 2 \\
\hline \multicolumn{4}{|c|}{ Platelet count $\left(\times 10^{9}\right.$ cells $\left./ \mathrm{L}\right)$} \\
\hline $0-80$ & 0 & 0 & 0 \\
\hline $81-300$ & 33 & 3 & 18 \\
\hline$>300$ & 9 & 3 & 3 \\
\hline
\end{tabular}

Note: There were no differences between the groups.

\section{Clinical Examples}

\section{Case 1}

A 69-year-old male amputated his left thumb fingertip (Tamai zone II) with a power saw. A long vein graft from the dorsum of his foot was harvested and anastomosed to the artery of the

Table 2 The results of the replantation in each group

\begin{tabular}{|l|l|l|l|}
\hline & $\begin{array}{l}\text { A: long } \\
\text { vein graft }\end{array}$ & $\begin{array}{l}\text { B: short } \\
\text { vein graft }\end{array}$ & $\begin{array}{l}\text { C: no } \\
\text { vein graft }\end{array}$ \\
\hline Survival & 42 & 5 & 17 \\
\hline $\begin{array}{l}\text { In the survived } \\
\text { fingertips }\end{array}$ & 0 & 0 & 1 \\
\hline $\begin{array}{l}\text { Arterial thrombosis } \\
\text { (salvaged by } \\
\text { reoperation) }\end{array}$ & 0 & 0 & 1 \\
\hline $\begin{array}{l}\text { Venous thrombosis } \\
\text { (salvaged by } \\
\text { reoperation) }\end{array}$ & 0 & 1 & 4 \\
\hline Necrosis & 0 & 5 & \\
\hline
\end{tabular}

Note: Two of the 17 surviving cases in group $C$ had vascular trouble that was salvaged by reoperation. 
Table 3 The use of a vein graft for venous anastomosis

\begin{tabular}{|l|l|l|l|}
\hline & $\begin{array}{l}\text { A: long } \\
\text { vein graft }\end{array}$ & $\begin{array}{l}\text { B: short } \\
\text { vein graft }\end{array}$ & $\begin{array}{l}\text { C: } \text { no } \\
\text { vein graft }\end{array}$ \\
\hline $\begin{array}{l}\text { No. of replantations } \\
\text { without vein graft } \\
\text { for venous anastomosis }\end{array}$ & 17 & 4 & 17 \\
\hline $\begin{array}{l}\text { No. of replantations } \\
\text { with vein graft for } \\
\text { venous anastomosis }\end{array}$ & 25 & 2 & 4 \\
\hline
\end{tabular}

fingertip. Then, the fingertip was sutured to the proximal stump without wiring, and arterial anastomosis was performed near the base of the thumb at the level of the interphalangeal joint. After arterial revascularization, the venous anastomosis was achieved using a remnant part of the vein graft. The replantation was successful, and after 1 year, the sensation and motion of the thumb recovered normally ( - Fig. 4 ).

\section{Case 2}

A 55-year-old male amputated his left index fingertip with a power saw. The replantation was performed in the same manner as described for case 1 and was successful. The replanted fingertip was slightly atrophic after 1 year, but the range of motion and sensation of the thumb were fully recovered (-Fig. 5).

\section{Discussion}

There have been many reports of fingertip replantations, and Li et $\mathrm{al}^{4}$ showed that among 211 fingertip replantation cases, the determinants of fingertip survival were the injury mechanism, use of a vein graft, smoking after the operation, platelet count, and fingertip storage method before the operation. In a systematic review of 2,273 fingertip replantations in 2011, the type of injury and repair of veins were the determinants of a successful outcome. ${ }^{8}$
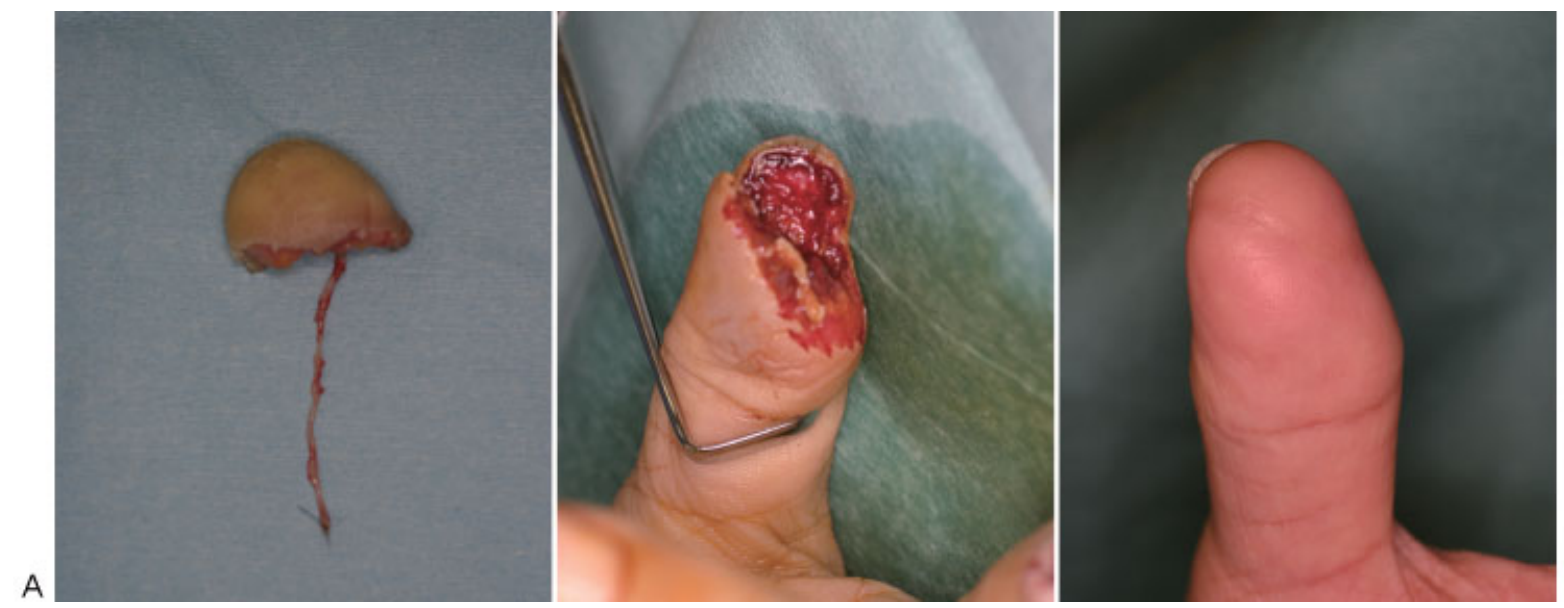

$B, C$

Fig. 4 Case 1: thumb tip amputation in a 69-year-old male treated with finger replantation using a long vein graft. (A) Amputated stump (Tamai zone II). (B) A long vein graft placed at the amputated fingertip. (C) Successful replantation at 12 months postoperation.
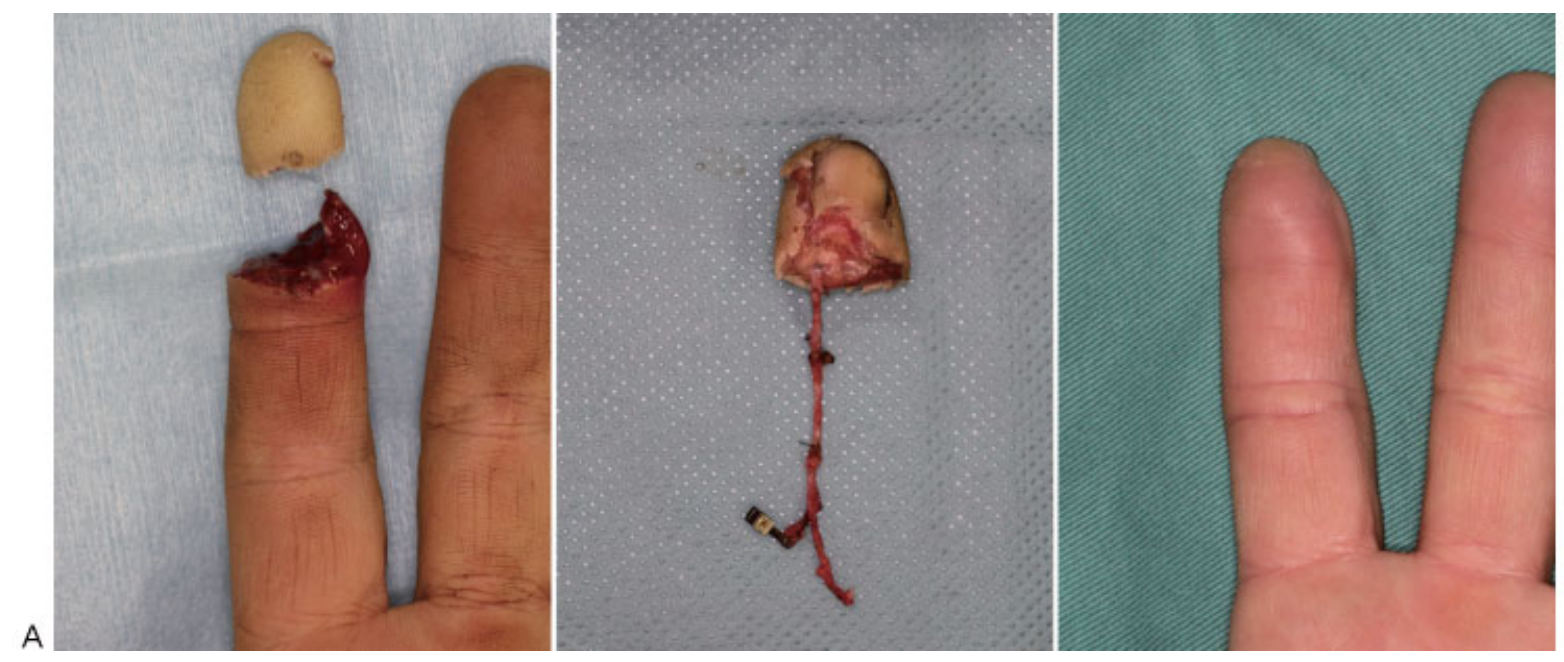

Fig. 5 Case 2: index fingertip amputation of a 55-year-old male. (A) Preoperative view. (B) A long vein graft placed at the amputated fingertip. (C) Successful result at 12 months postoperation. 
In our series of 69 fingertip replantations supervised by one senior surgeon, there was no statistically significant difference in the injury mechanism or platelet count between the groups. All patients remained in the hospital after replantation, where they did not smoke. Finally, all of the fingertips were kept wet and cold before replantation. Therefore, the patient factors that affect the results can be considered equivalent across the three groups. In each group, the drainage vein was repaired in all cases.

The advantage of using a vein graft for finger replantation has been described, ${ }^{7}$ and in this series, the type of vein graft also had a statistically significant influence on the success rate of the fingertip replantation. Specifically, a long vein graft was more useful than a short graft for arterial anastomosis.

While the results of this study suggest that the use of a long vein graft contributed to the superior survival rate in group $A$, two other factors may be involved that are not associated with the surgeon's technique. First, injecting saline solution into the vein graft can reveal minor damage or small branches in the artery of the fingertip that were not previously discovered or cannot be seen in situ (-Fig. 4). Second, the point of the digital artery chosen for anastomosis is far proximal to the point that is typically thought to be sufficient for use. This provides a proximal arterial stump with less damage and a decreased propensity to spasm, leading to stable and sufficient arterial inflow.

The surgeons in this report attempted to repair the drainage vein whenever possible, and venous repair was achieved in all 69 fingertips. In this study, utilizing a vein graft for venous anastomosis also significantly improved the survival rate $(p=0.04)$. While aggressive use of a vein graft for venous anastomosis was not our specific strategy, we used a vein graft for venous anastomosis without hesitation, if necessary. In group A, each patient was more likely to have a remnant vein from the original graft, and therefore a vein graft was used more often in this group than the other groups (-Fig. 6). Without a vein graft, the tension at the anastomosis site may be high, resulting in thrombosis. A previous study has found that venous repair is associated with statistically higher success rates. ${ }^{8}$ The remnant vein graft may also increase the venous repair rate because it aids in the anastomosis of the two veins, which are often so far apart that a surgeon would not attempt the anastomosis without a vein graft.

Ikeda et $\mathrm{al}^{9}$ reported that the "pre-osteosynthesis vein graft technique" was useful for the anastomosis of the veins of the fingertip, which is usually the most difficult procedure. However, the vein of the fingertip is usually found just below the dermis. Performing the venous anastomosis on the back table is as difficult as performing it in situ. Some surgeons may achieve venous anastomosis before arterial anastomosis if possible. ${ }^{10}$ However, the vein found before arterial revascularization may not be reliable because it is unknown whether the venous return truly comes from the vein. Injection of heparinized saline solution through the stump of the grafted vein can be helpful for finding a returning vein or veins, but it is usually difficult to find because the saline is clear and it is difficult to see the venous back flow. The use of indocyanine green (ICG) video angiography to detect the vein

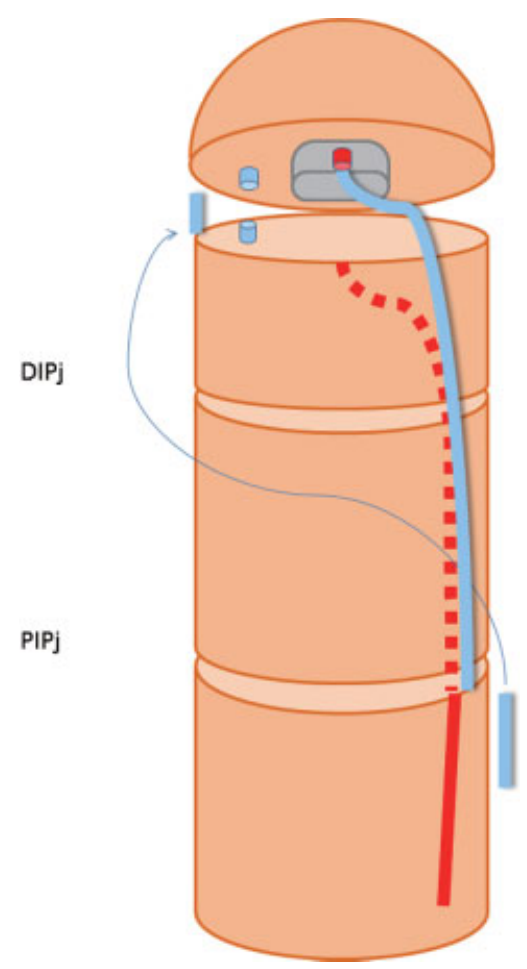

Fig. 6 Anastomosis between the vein graft and the proximal digital artery at the level of the proximal interphalangeal joint (PIPj) is easy for even beginner microsurgeons. The remnant vein graft is useful for the anastomosis of the veins if necessary. DIPj, Distal interphalangeal joint.

after revascularization has been described. ${ }^{11}$ This technique is also available just after the vein graft is attached and the vein is marked. Even using ICG videoangiography, we opt to perform venous anastomosis after revascularization because it is still unclear whether the vein is in good condition.

In most of the literature, the experience level of the microsurgeons performing microvascular anastomoses was not described. $\mathrm{Li}^{4}$ reported that anastomosis in the fingertip was not difficult for experienced surgeons. Koshima ${ }^{12}$ also reported that fingertip replantation requires a high level of microsurgical technique and that it should not be performed by an inexperienced microsurgeon, but rather by a microsurgeon who has substantial training in and commitment to this type of "supermicrosurgery." However, in the emergency setting, expert microsurgeons cannot always attend. We, therefore, must allow young surgeons to participate in the operation and develop new microsurgery experts, though this practice should not lead to failure for the patients who expect high survival rates as reported in the literature.

In this series, younger surgeons participated in the operation as operators, though an experienced surgeon (T.S.) reviewed the maneuver and repaired it if necessary. The younger surgeons had 1 to 5 years of plastic surgery experience. Even when the operation was performed by young surgeons, the surgical results in each group were as good as those of former reports, ${ }^{2-7}$ and in particular, the results in group A were very good (100\% survival). 
The artery in the fingertip is usually found near the bone of the distal phalanx and is deep from the skin surface. The available space for the anastomosis is very small and the anastomosis itself is difficult when the tip is fixed to the proximal finger stump before anastomosis. The advantage of the current method is that it not only makes anastomosis easier but also facilitates the identification and repair of damage or incomplete anastomosis. Injection of heparinized saline solution through the vein graft can reveal minor damage in the distal artery that could not be detected after fixation and reperfusion. Repairing a poor anastomosis in the distal phalanx is usually very difficult, even for experienced surgeons, but it is much easier on the back table where less experienced surgeons can gain experience with anastomosis.

In this consecutive study, no fingertip failed to survive in group A, but this does not guarantee the prospective success. If the next case was unsuccessful, the statistical result may differ from that of this study.

\section{Conclusion}

Operative technique is a part of medicine and must be passed down to younger surgeons. A difficult technique that only a few specialized surgeons can perform is not ideal in medicine. In this series, the author reports a procedure for fingertip replantation that enabled less experienced surgeons to gain experience with these techniques while maintaining a high success rate. We recommend the use of a long vein graft for arterial anastomosis, along with venous anastomosis using the vein graft remnant, to optimize surgical success in the emergency setting.

\section{References}

1 Komatsu S, Tamai S. Successful replantation of a completely cut-off thumb. Plast Reconstr Surg 1968;42:375-376

2 Hahn HO, Jung SG. Results of replantation of amputated fingertips in 450 patients. J Reconstr Microsurg 2006;22(6): 407-413

3 Ozcelik IB, Tuncer S, Purisa H, et al. Sensory outcome of fingertip replantations without nerve repair. Microsurgery 2008;28(7): 524-530

4 Li J, Guo Z, Zhu Q et al. Fingertip replantation: determinants of survival. Plast Reconstr Surg 2008;122(3):833-839

5 Zhang X, Wen S, Wang B, Wang Q, Li C, Zhu H. Reconstruction of circulation in the fingertip without vein repair in zone I replantation. J Hand Surg Am 2008;33(9):1597-1601

6 Hasuo T, Nishi G, Tsuchiya D, Otsuka T. Fingertip replantations: importance of venous anastomosis and the clinical results. Hand Surg 2009;14(1):1-6

7 Yan H, Jackson WD, Songcharoen S, et al. Vein grafting in fingertip replantations. Microsurgery 2009;29(4):275-281

8 Sebastin SJ, Chung KC. A systematic review of the outcomes of replantation of distal digital amputation. Plast Reconstr Surg 2011; 128(3):723-737

9 Ikeda K, Morikawa S, Hashimoto F, Tomita K. Fingertip replantation: pre-osteosynthesis vein graft technique. Microsurgery 1994; 15(6):430-432

10 Sabapathy SR, Venkatramani H, Bharathi RR, Sebastin SJ. Distal fingertip replantation without skeletal fixation. J Reconstr Microsurg 2005;21(1):11-13

11 Kurita M, Shiraishi T, Ozaki M, Takushima A, Harii K. Usefulness of microscope-based ICG videoangiography for detection of the dominant drainage vein in fingertip replantation. J Plast Reconstr Aesthet Surg 2010;63(12):2200-2201

12 Koshima I. Atypical arteorile anastomoses for fingertip replantations under digital block. J Plast Reconstr Aesthet Surg 2008; 61:84-87 